\title{
Evaluation of tubal patency by sonosalpingography is as good as hysterosalpingography in infertile women
}

\author{
C. Santhana Lakshmi ${ }^{1 *}$, Kumara Sampath ${ }^{2}$, Parvatha Varthini ${ }^{1}$
}

\begin{abstract}
${ }^{1}$ Department of Obstetrics and Gynecology, ${ }^{2}$ Department of Radiodiagnosis, Karpaga Vinayaga Institute of Medical Sciences and Research Centre, Madhurantagam, Tamil Nadu, India
\end{abstract}

Received: 15 September 2017

Accepted: 06 October 2017

\author{
*Correspondence: \\ Dr. C. Santhana Lakshmi, \\ E-mail: santhanalakshmi811@gmail.com
}

Copyright: (C) the author(s), publisher and licensee Medip Academy. This is an open-access article distributed under the terms of the Creative Commons Attribution Non-Commercial License, which permits unrestricted non-commercial use, distribution, and reproduction in any medium, provided the original work is properly cited.

\begin{abstract}
Background: Tubal pathology is one of the causes of infertility in sub fertile couples. Therefore, evaluation of fallopian tubes forms an essential part of evaluation in a sub fertile woman. The aim of the study was to compare the efficacy of sonosalpingography which is a less invasive method when compared to hysterosalpingogram for evaluation of utero-tubal factor in females.

Methods: A total of 95 patients 69 with primary infertility and 26 with secondary infertility attending our Obstetrics and Gynecology department were recruited for the study from June 2016 to July 2017. All the study subjects underwent Sonosalpingography on day $5^{\text {th }}$ to $7^{\text {th }}$ and Hysterosalpingography on $7^{\text {th }}$ to $9^{\text {th }}$ day of the menstrual cycle. Data was collected and compared to assess the sensitivity and specificity of sonosalpingography over hysterosalpingography. Statistical analysis was done by using SPSS software version 16.0.

Results: Sonosalpingography (SSG) has $97 \%$ sensitivity and $94 \%$ specificity in comparison to hysterosalpingography (HSG). Analysis of the raw data gave positive predictive value of $98.3 \%$ and negative predictive value of $75 \%$. From the results of this study it clear that there is no statistically significant difference $(p=0.237)$ between the results of the two methods (SSG and HSG).

Conclusions: As sonosalpingogrpahy has high sensitivity and specificity and is less invasive. It should be used initially to assess tubal patency in cases of infertility. SSG is found to be a reliable, relatively less expensive diagnostic and therapeutic procedure in the management of infertility in females. Easy availability and accessibility of ultrasound in all primary health care centers definitely can prove superior to conventional method of diagnosis of tubal patency in such patient.
\end{abstract}

Keywords: Hysterosalpingography, Infertility, Radiodiagnosis, Sonosalpingography, Tubal patency

\section{INTRODUCTION}

Tubal pathology is a cause of sub-fertility in $25-35 \%$ of sub fertile couples. ${ }^{1}$ Evaluation of fallopian tubes therefore forms an essential part of evaluation of a sub fertile female. ${ }^{1}$ The incidence of tubal disease in infertility varies from country to country.

In India it has been estimated to be about $40 \% .^{2}$ Tubal factors affect fertility in $18 \%$ to $81 \%$ of female infertile patients, depending on population. ${ }^{1,2}$ Hence, evaluation of tubal patency is essential in investigation of female infertility. Tubal factors not only contribute to major etiologic factors but also pose perplexing problems in diagnosis.

The prevalence of pelvic inflammatory disease, genital tract tuberculosis, and chronic infection is quite common in our country and hence the incidence of tubal factor in infertile women is high. ${ }^{4,5}$ 
Disorders of the tube may be pathological or functional. Pathological blockage can be secondary to any pelvic pathology, particularly inflammatory in origin, or it may be due to the congenital defects in the tube. ${ }^{6,7}$

Several investigations have been used since decades to evaluate the tubal patency. Noteworthy procedures are hysterosalpingography, laparoscopic chromopertubation, salpingoscopy, falloposcopy, radionuclide hysterosalpingography, and transvaginal sonosalpingography. This study is undertaken to compare sonosalpingography and hysterosalpingography in the evaluation of tubal patency in sub fertile or infertile women. ${ }^{3-7}$

Therefore, the evaluation of uterotubal factors is an essential step in infertility management. There are various invasive and noninvasive diagnostic procedures to evaluate uterine and/or tubal pathology. ${ }^{8}$ The noninvasive or minimally invasive modalities are ultrasonography, sonosalpingography (SSG), and magnetic resonance imaging. The invasive modalities are hysterosalpingography (HSG), hysteroscopy, and laparoscopy. ${ }^{7-10}$ It would be beneficial if a way could be found to assess the uterine and/or tubal pathology using a relatively minimal invasive approach and also that is cost-effective.

The basic principle of SSG is to distend the uterine cavity with isotonic saline, which will delineate the contour, identify intrauterine pathology and thickness of endometrium, and also measure the presence of fluid in the pouch of Douglas. ${ }^{8,9}$ Sonosalpingography is more precise in accurately detecting intrauterine abnormalities and measuring endometrial thickness and also the tubal patency ${ }^{10}$. It is simple, safe, and easy to perform and unlike HSG is devoid of radiation hazards and the risk of allergy to iodine contrast. ${ }^{8,11}$ It is also noninvasive and does not require anesthesia unlike hysteroscopy and laparoscopy. ${ }^{8-11}$ The present study is done to assess the diagnostic accuracy of sonohysterography as compared with HSG.

\section{METHODS}

The study was conducted in the department of Obstetrics and Gynaecology of Karpaga Vinayaga Institute of Medical Sciences and Research Center, Madhurantagm, Tamilnadu in collaboration with department of Radiology during March 2016 and June 2017. All patients with primary infertility who fit in the inclusion criteria were selected in the study. The patients were initially counselled along with their partner and a through a structured questionnaire history of both the partners was obtained which was followed by a general and pelvic examination of female partner. The study was approved by institutional ethics committee and a written informed consent was obtained from all the participants after explaining the purpose of the study.

\section{Inclusion criteria}

Patients with no other medical illness apart from infertility complaint aged between 20-40years and willing to participate were recruited for the study.

\section{Exclusion criteria}

Patients who are less than 19 years and above 40 years were excluded from the study. Also, patients with pelvic inflammatory disease (PID) were excluded from the study.

To assess the tubal factors, an informed consent was taken from all the patients and was posted for specialized tests as hysterosalpingography, sonosalpingography and findings of all the procedure were recorded. Sonosalpingography procedure was done during the proliferative phase of menstrual cycle between $5^{\text {th }}$ to $7^{\text {th }}$ days. The procedure involves instillation of normal saline into the endometrial cavity during vaginal sonography and inspection of the tubes for spillage. The vulva and vagina was cleaned with antiseptic solution, a sterile speculum introduced into the vagina and anterior lip of cervix was held with vualsellum. A Foley catheter of no 8 size introduced beyond the internal os and balloon distended with $1-2 \mathrm{ml}$ of normal saline to prevent retrograde leakage of saline into the vagina. Sterile saline about $30 \mathrm{ml}$ was injected slowly through the catheter under continuous sonography control. The uterus scanned systematically in sagittal and coronal planes to delineate the entire endometrial cavity and appropriate image recorded. Tubal patency was assessed by Doppler and Bmode ultrasound and by fluid accumulation in the pouch of douglas.

HSG was performed prior to ovulation between menstrual cycle days 7 th to 9 th days to avoid pregnancy. Radio opaque dye (Trazograf 76\%, Made in Spain) was injected into the uterine cavity and two films one immediate and other film after 5 minutes were taken. All the data was collected and statistical analysis was done with SPSS version 16.0.

\section{Statistical analysis}

Statistical analysis was performed using SPSS 16.0 software. Unpaired t-test was used to analyze continuous data. Categorical data was compared using Chi-square test. $\mathrm{P}<0.05$ was taken as statistically significant. Relative risk was calculated for abnormal UA PI, UA RI, UA S/D, MCA PI and cerebral-umbilical PI ratio. Multivariate regression was used to analyze effect of multiple variables.

\section{RESULTS}

The present study was carried out in 95 patients. All the subjects were in the age range 20-40 year. In Table 1 , the age wise distribution of patient was shown in which the 
youngest one was 20 years and the oldest was 37 years old. Mean age of the study population is $26.9 \pm 4.9$ years. Out of 95 patients $69(72.6 \%)$ patients were of primary infertile, while $26(27.4 \%)$ patients were of secondary infertility. In $72.6 \%$ of the patient reason for performing diagnostic test for tubal patency was primary infertility and in $27.4 \%$ it was secondary infertility.

Table 1: Demographic features of the studied population.

\begin{tabular}{|c|c|c|}
\hline Age & $\begin{array}{l}\text { Primary } \\
\text { infertility } \\
(n=69)\end{array}$ & $\begin{array}{l}\text { Secondary } \\
\text { infertility } \\
(\mathrm{n}=\mathbf{2 6})\end{array}$ \\
\hline 20-25 years & 32 & 03 \\
\hline $26-30$ & 21 & 07 \\
\hline $31-35$ & 11 & 10 \\
\hline$>35$ years & 05 & 06 \\
\hline Total & 69 & 26 \\
\hline \multicolumn{3}{|l|}{ Working status } \\
\hline Working women & 17 & 02 \\
\hline Women not working & 39 & 21 \\
\hline $\begin{array}{l}\text { Worked in the past but at } \\
\text { present not working }\end{array}$ & 13 & 03 \\
\hline Total & 69 & 26 \\
\hline
\end{tabular}

From the Table 2 results it was clear that the data obtained after analysis of SSG and HSG data of all the participants $(n=95)$ there was no significant difference between the results of SSG and HSG.

Table 2: Comparison of the SSG with HSG among all the patients.

\begin{tabular}{|lll|}
\hline & $\begin{array}{l}\text { Sono- } \\
\text { salpingography } \\
\text { (SSG) }\end{array}$ & $\begin{array}{l}\text { Hystero- } \\
\text { salpingography } \\
\text { (HSG) }\end{array}$ \\
\hline $\begin{array}{l}\text { Bilateral tubal } \\
\text { patent }\end{array}$ & 68 & 65 \\
\hline Right tubal block & 8 & 11 \\
\hline Left tubal block & 11 & 9 \\
\hline $\begin{array}{l}\text { Bilateral tubal } \\
\text { block }\end{array}$ & 8 & 10 \\
\hline
\end{tabular}

Table 3 shows the diagnosis of pelvic pathology by SSG and HSG in study population. Tubal pathologies like tuboovarian mass, hydrosalpinx, PCOS, and other pelvic pathology like endometriosis, fibroid uterus and endometrial polyp were better detected by SSG compared to HSG.

In all, 190 fallopian tubes were examined. Patency of the fallopian tube was established by SSG in 68 of 95 $(71.5 \%)$ tubes examined while HSG showed 65 of 95 $(68.4 \%)$ tubes as patent. When the results of SSG were compared with those of HSG, there was a $92 \%$ agreement on the right and $89 \%$ on the left (mean concordance $89 \%$ ). The overall sensitivity of SSG in diagnosing tubal patency was $94 \%$ and the specificity $97 \%$. The positive predictive value for tubal patency by SSG was $98 \%$ and the negative predictive value $77 \%$.

Table 3: Associated pelvic pathology detected by SSG and HSG.

\begin{tabular}{|lll|}
\hline & $\begin{array}{l}\text { Sono- } \\
\text { salpingography } \\
\text { (SSG) }\end{array}$ & $\begin{array}{l}\text { Hystero- } \\
\text { salpingography } \\
\text { (HSG) }\end{array}$ \\
\hline Fibroid uterus & 03 & - \\
\hline Endometriosis & 06 & - \\
\hline $\begin{array}{l}\text { Endometrial } \\
\text { polyp }\end{array}$ & 01 & - \\
\hline $\begin{array}{l}\text { Tuboovarian } \\
\text { mass }\end{array}$ & 07 & - \\
\hline Hydrosalpinx & 05 & 05 \\
\hline Septate uterus & - & 02 \\
\hline PCOS & 09 & - \\
\hline None & 64 & 88 \\
\hline Total & 95 & 95 \\
\hline
\end{tabular}

Overall the agreement between HSG and SSG was established in 172 of 190 (90.5\%) fallopian tubes. The sensitivity of sonosalpingography (SSG) in diagnosing tubal patency was $97 \%$ and the specificity $94 \%$. Analysis of the raw data gave positive predictive value of $98.3 \%$ and negative predictive value of $75 \%$. It is accepted that there is no statistically significant difference $(p=0.237)$ between the results of the two methods (HSG and SHSG). SSG is found to be a reliable, relatively less expensive diagnostic and therapeutic procedure in the management of infertility in females. By using binomial proportion test there is no significant difference between results of SSG compare to HSG. Acceptability was $100 \%$ in SSG compared to $96 \%$ in HSG. Comparison made between the two methods showed no significant difference $(\mathrm{p}=0.35)$ in the outcome of these examinations.

\section{DISCUSSION}

Hysterosalpingography became an accepted procedure in 1925 ever since the discovery of an effective medium lipiodol. However, it has its limitations and complications. It cannot be done in cases of pelvic infections and active uterine bleeding. It is associated with risks such as iodine allergy, pelvic infections, and pain. It can cause venous or lymphatic intravasation of medium and also involves the risks of radiation exposure. Transient distortion of uterine cavity by blood, mucus, debris, and air bubbles may produce false positive results. For a long time, HSG was the sole procedure to detect intra uterine abnormalities and tubal patency. But it has an increased risk of infection and also has high false positive rates. ${ }^{10-12}$

In the past two decades there was lot of advancement in the medical technology and management of infertility. Saline infusion sonohysterography or SSG is the term for ultrasound imaging of the uterine cavity, using sterile 
saline solution as a negative contrast medium. Sonosalpingography is a low-tech, low-cost, transabdominal sonography, which obviates the need for diagnostic hysteroscopy in cases of abnormal uterine bleeding, reproductive failure, or abnormal endometrial images obtained with any modality. ${ }^{11,13}$ Evaluation of tubal patency is necessary because any treatment, such as induction of ovulation and artificial insemination, given without making sure that the tubes are patent may be a futile effort. There has been a rising demand for accurate and non-invasive diagnostic procedures, and this has fostered significant innovations in the technique and equipment used for evaluating infertility. ${ }^{14}$

In present study bilateral tube patency was reported in 68 patients by sonsalpingography, in 65 patients by hysterosalpingography. In the present study bilateral tubal blockage was demonstrated in 8 patients by sonosalpingography, in 10 patients by hysterosalpingography (Table 2). The sensitivity of sonosalpingography for detecting tubal blockage has been calculated to be $98 \%$. The specificity of true negatives was $80.6 \%$. The positive predictive value was $89.7 \%$, negative predictive value being $100 \%$. The overall agreement of sonosalpingography with that of hysterosalpingography for patent and blocked tube was $94 \%$. The sensitivity of hysterosalpingigraphy for detecting tubal blockage was calculated to $91 \%$. The specificity was $73.13 \%$. The positive and negative predictive value of hysterosalpingography was $77 \%$ and $94 \%$ respectively. The percentage of false negative was $62 \%$ and that of false positive was $35 \%$. The total accuracy was calculated to be $80 \%$.

Sonosalpingography picked up the fibroid uterus in three patients, endometriosis in six patients, endometrial polyp in one patient, tuboovarian mass in 7 patients, hydrosalpinx in 5 patients, PCOS in nine patients, while hysterosalpingography picked up hydrosalpinx in 5 patients, the septate uterus in two cases which could not be visualized on SSG. By SSG septate uterus was diagnosed as Arcuate uterus (Table 3).

The sonosalpingography has also certain other advantage it is outpatient procedure, less time consuming and cost effective, it is a non-invasive procedure, no anesthesia is required. It helps in the diagnosis of both uterine anomalies and pelvic pathologies. ${ }^{11,15-17}$ It causes no radiation hazards, it avoids allergic reaction. Hysterosalpingography has certain disadvantages. For example, it detects only the endotubal pathology, can cause allergic manifestation and reaction to the drugs used known hydrosalpinx, acute PID or cervicitis and adenaxal mass palpable on bimanual examination all constitute contraindication to hysterosalpingography. It also exposes women to radiation. However, hysterosalpingography has the advantage of detecting the site of blockage, isthmic nodosa, benign polyps and tubal endrometriosis. $^{14}$
All in all ninety five infertile women presenting with infertility were recruited for the study. Tubal factor was studied by sonosalpingography and hysterosalpingography performed during the same menstrual cycle and the results were compared. Out of 95 patients 69 patients $(63.4 \%)$ were of primary infertility and remaining 26 patients $(36.6 \%)$ were of secondary infertility. ${ }^{16}$

Allahabadia GN found $82 \%$ (41 out of 50 cases) tubes bilaterally patent by sonosalpingography $74 \%$ (37 cases) by hysterosalpingography and $82 \%$ (41 cases) by laproscopy. ${ }^{14}$

A study was done on 40 infertility patients in whom the accuracy of SSG was compared with HSG and laparoscopy with chromopertubation for tubal patency. They found that SSG was having 93\% correlation with HSG. Thus, they concluded that transvaginal SSG is a simple, cost-effective, noninvasive test that can be used as screening procedure for the assessment of tubal patency in the initial workup of infertile women. ${ }^{17}$

There are few studies done by researchers to assess the diagnostic accuracy of ultrasound in assessing the tubal patency and other uterine cavity diseases 16-18. Diaferia $\mathrm{D}$ and his co authors have studied 65 infertile women who underwent sonohysterography, conventional TVS, HSG, and hysteroscopy. ${ }^{16-18}$ The objective of this study was to evaluate the diagnostic accuracy of sonohysterography in uterine cavity diseases in infertile patients and comparing its results with those of HSG and TVS. Sonohysterography had the same diagnostic accuracy as the criterion standard (hysteroscopy), whereas HSG showed a sensitivity of $50 \%$. For uterine malformations, HSG had a sensitivity of $77.8 \%$, whereas TVS and HSG both had sensitivity of $75 \%$ in detection of intrauterine adhesion and PPV of $42.9 \%$ and $50 \%$. Thus, they concluded that was in general the most accurate test, and its diagnostic accuracy was markedly superior. In diagnosis of intrauterine adhesions, SSG had limited accuracy similar to that obtained by HSG with a high false-positive diagnosis rate. These results were consistent with our results, which showed that SSG had a sensitivity of $95 \%$ for detection of tubal patency as compared with the sensitivity of HSG $(91 \%)$ for detection of tubal patency. In a study of 98 infertile patients who underwent sonohysterography and subsequently compared with hysteroscopy for the diagnosis of intrauterine pathology, it was found that sensitivity, specificity, and accuracy of TVS compared with hysteroscopy were $92 \%, 86 \%$, and $89 \%$, respectively. Sensitivity, specificity, and accuracy of SSG compared with hysteroscopy were 98\%, 93\%, and 96\%, respectively. Comparing SSG with hysteroscopy, they found only one false negative $(1.0 \%)$ and 3 false-positive $(3.0 \%)$ results at SSG. 
HSG most common technique used to diagnose tubal patency which is associated with following disadvantages. ${ }^{17-19}$

- Insertion of HSG cannula is painful compared to insertion of Foley's catheter in SSG

- It can cause allergic reaction to dye used for it.

As development, updation and wide use of ultrasonography, nowadays ultrasonography has become popular for evaluating many gynaecological pathologies. ${ }^{9,11-14}$

SSG, a term coined in 1993, not used widely even it's a non-invasive so we decided to compare it with the widely used conventional method HSG. ${ }^{12}$ Results and analysis of our study showed that SSG is equally sensitive and specific in diagnosing tubal patency with no significant difference by using binomial proportion test.

We found certain advantages in techniques of SSG:

- It is outpatient procedure and can be performed while doing first routine ultrasound of infertile women, hence cost effective also.

- It helps in diagnosis of various uterine and tubal pathologies.

- There are no radiation hazards.

- No allergic reaction.

- If done under aseptic precautions there is no infectious morbidity.

- It can be done in Primary Health Centers also

Hence the study clearly showed that SSG can be used as baseline investigation in all infertile women. It is equally efficient method as HSG with many advantages.

\section{CONCLUSION}

In conclusion, SSG is a comparatively reliable, simple and relatively inexpensive diagnostic and therapeutic procedure in the management of female infertility. It is also relatively less invasive technique without much of complications. With expected improvement in this techniques and future advances in sonographic tissue characterization, it is believed that SSG will be a first line diagnostic procedure in the evaluation of tubal patency. Easy availability and accessibility of ultrasound in all primary health care centers definitely can prove superior to conventional method of diagnosis of tubal patency in such patient.

\section{ACKNOWLEDGMENTS}

Authors would like to thank the patients who have participated in the study. Authors would like to thank, Dr Viswanathan, Professor and HOD of Obstetrics and Gynecology of Karpaga Vinyaga Institute of Medical Sciences and Research Center, and Dr Geetha Prasad, Professor of Obstetrics and Gynecology of Karpaga
Vinyaga Institute of Medical Sciences and Research Center for their support in accomplishing this project.

Funding: No funding sources

Conflict of interest: None declared

Ethical approval: The study was approved by the Institutional Ethics Committee

\section{REFERENCES}

1. Kulkarni NN, Patel R, Patel NR, Patil AB. Comparative study of sonosalpingography versus hysterosalpingography for tubal patency test. Int $\mathbf{J}$ Reprod Contracept Obstet Gynecol. 2016;5:3300-3.

2. Laurence AM, Michael RS. Infertility evaluation and treatment. In: Imaging of the Reproductive Tract in Infertile Women: Hysterosalpingography, Ultrasonography and Magnetic Resonance Imaging. WB Saunders Company;1995:300-3. Chapter 23.

3. Bayasgalan G, Naranbat D, Tsedmaa B, Tsogmaa B, Sukhee D, Amarjargal O et al. Clinical patterns and major causes of infertility in Mongolia. J Obstet Gynecol Res. 2004;30:386-393.

4. Chiamchanya C, Su-angkawatin W. Study of the causes and the results of treatment in infertile couples at Thammasat Hospital between 1999-2004. J Med Assoc Thailand. 2008;91:805-812.

5. Stewart-Smythe GW, van Iddekinge B. Lessons learned from infertility investigations in the public sector. S Afr Med J. 2003;3:141-3.

6. Steven RG. Saline infusion sonohysterography. Clin Obst Gynecol. 2000;39(1):248-258.

7. Farhi J, Ben-Haroush A. Distribution of causes of infertility in patients attending primary fertility clinics in Israel. IMAJ. 2011;13:51-54.

8. Rao KS. Text Book of Diagnostic Radiology and Imaging. $1^{\text {st }}$ ed. India: Jaypee Publications; 1997.

9. Kore S, Hegde A, Nair S. Sonography for assessment of tubal potency: our experience. J Obstet Gynecol India. 2000;50(2):636.

10. Panchal S, Nagori C. Imaging techniques for assessment of tubal status. J Hum Reprod Sci. 2014;7:2-12.

11. Rahman M, Sinha DK. A cost-effective approach in the evaluation of female infertility. Obstet Gynecol Ind. 2002;52(1):105-7.

12. Sergio RS, Marcos MBBdR, Aroldo FC. Diagnostic accuracy of sonohysterography, transvaginal sonography and hysterosalpingography in patients with uterine cavity diseases. Fertil Steril. 2000;73(2):406-411.

13. Saanida MP, Beenamol S. A comparative study between sonohysterosalpingography and hysterosalpingography in the evaluation of infertility. J Evol Med Dent Sci. 2013 Feb 18;2(7):702-9.

14. Allabadia GN. Fallopian tubes and ultrasonography: the Sion experience. Fertil Steril. 1992;58:901-7.

15. Deichert U. Evaluation of tubal patency by hysterosalpingocontrastsonography (HYCOSY). In: Kupesie S. Ziegler D. (eds). Ultrasound and 
Infertility. New York The Parthenon publishing group;2000:263-284.

16. Diaferia D, Ragni G, Vegetti. Sonohysterography for uterine cavity evaluation in infertility work-up. Fertil Steril. 2000;74(3):530.

17. Johnson N, Vandekerckhove P, Watson A, Lilford R, Harada T, Hughes E. Tubal flushing for subfertility. Cochrane Database Syst Rev. 2005:CD003718.

18. Parihar M. Transcervical tubal evaluation. In: Infertility Principles and Practice. New Delhi, India: B. I. Publications, Pvt. Ltd;2004:44-49.
19. Shailesh K, Aparna H, Sudha N. Sonosalpingography for assessment of tubal patency: our experience. J Obstet Gynecol India. 2000;50(2):63-66.

Cite this article as: Lakshmi CS, Sampath K, Varthini P. Evaluation of tubal patency by sonosalpingography is as good as

hysterosalpingography in infertile women. Int $\mathbf{J}$

Reprod Contracept Obstet Gynecol 2017;6:5129-34. 